\section{Botulinum toxin} treatment of spasticity in diplegic cerebral palsy: a randomized, double-blind, placebo-controlled, dose-ranging study

R Baker*, Musgrave Park Hospital, Belfast, Northern Ireland. M Jasinski, Dzieciecy Szpital Kliniczny AM W Lublinie, Lublin; I Maciag-Tymecka, Wojewodzki Oddzial Rehabilitacji Dzieci I Mlodziezy, Gdansk;

J Michalowska-Mrozek, Instytut Pomnik-Centrum Zdrowia Dziecka, Warszawa;

M Bonikowski, Dzial Neurologii Dzieciecy Swzpznoz, Zagórze, k/Warsawy, Poland.

L Carr, The Wolfson Centre, Great Ormond Street Hospital for Sick Children NHS Trust, London;

J MacLean, Dundee Teaching Hospitals NHS Trust Hospital, Dundee;

J-P Lin, Newcomen Centre, Guy's \& St Thomas' Hospital Trust, London, UK.

B Lynch, Central Remedial Clinic, Dublin, Ireland. T Theologis, Nuffield Orthopaedic NHS Trust, Oxford UK. J Wendorff, Centrum Zdrowia Matki Polki, Lódż, Poland. P Eunson, Edinburgh Sick Children's NHS Trust, Edinburgh; A Cosgrove, Musgrave Park Hospital, Belfast, Northern Ireland.

*Correspondence to first author at Hugh Williamson Gait Analysis Laboratory, Royal Children's Hospital, Flemington Road, Parkville, Victoria 3052, Australia. E-mail: bakerr@cryptic.rch.unimelb.edu.au

This study evaluated the efficacy and safety of three doses of botulinum toxin A (BTX-A; Dysport ${ }^{\circledR}$ ) in 125 patients (mean age 5.2 years, SD 2; 54\% male) with dynamic equinus spasticity during walking. Participants were randomized to receive Dysport $(10,20$, or 30 units $/ \mathrm{kg}$ ) or placebo to the gastrocnemius muscle of both legs. Muscle length was calculated from electrogoniometric measurements and the change in the dynamic component of gastrocnemius shortening at four weeks was prospectively identified as the primary outcome measure. All treatment groups showed statistically significant decreases in dynamic component compared with placebo at 4 weeks. Mean improvement in dynamic component was most pronounced in the 20 units $/ \mathrm{kg}$ group, being equivalent to an increase in dorsiflexion with the knee extended at $19^{\circ}$, and was still present at 16 weeks. The safety profile of the toxin appears satisfactory.
Since the first descriptions of the benefit of botulinum toxin $\mathrm{A}$ (BTX-A) for the treatment of spasticity in children with cerebral palsy (CP; Koman et al. 1993, 1994; Cosgrove et al. 1994), its use has become routine in many centres. In a number of controlled studies, beneficial effects of toxin treatment, over and above the placebo effects, have been reported for lowerlimb spasticity associated with CP (Chutorian and Root 1995; Corry et al. 1997, 1999; Sutherland et al. 1999; Koman et al. 2000). In addition, the beneficial effect of BTX-A has been demonstrated when compared with splinting and stretching casts (Corry et al. 1998, Flett et al. 1999).

In several different studies, toxin injections have been administered to a variety of muscles in the lower limb, including hamstrings (Corry et al. 1999), iliopsoas (Heinen et al. 1997b), adductors (Carr et al. 1998), and tibialis posterior (Sanchez-Carpintero and Narbona 1997, Mousny and Allington 1999), in addition to muscles of the upper limb (Corry et al. 1997, Friedman et al. 2000). However, in most studies in children with CP, injections have been made into the gastrocnemius muscle (Koman et al. 1993, 1994; Cosgrove et al. 1994; Chutorian and Root 1995; Corry et al. 1998; Flett et al. 1999; Eames et al. 1999; Sutherland et al. 1999; Boyd et al. 2000; Koman et al. 2000).

To assess the outcome of the treatment at the level of 'body structure and function' (as defined by the World Health Organization 1999), many different measures have been used, including electromyography (Hesse et al. 1994, Heinen et al. 1997b), goniometry (Cosgrove et al. 1994, Denislic and Meh 1995, Heinen et al. 1997a), muscle torque (Corry et al. 1997), the Ashworth scale (Calderon-Gonzalez et al. 1994, Denislic and Meh 1995, Heinen et al. 1997b) and general gait analysis (Cosgrove et al. 1994, Sutherland et al. 1999). Eames and colleagues (1999) investigated the effect of BTX-A injections on muscle length and showed that a single injection into the calf led to an increase in gastrocnemius muscle length during gait. They also defined the 'dynamic component' of muscle shortening as the difference between the maximum gastrocnemius length recorded during passive examination and the maximum length recorded during walking. They showed a linear relationship between this dynamic component and the response to BTX-A injection. Consequently, at the level of 'body structure and function' this is probably the most sensitive indicator of a response to BTX-A injections.

Although it is clear that the toxin has a beneficial effect at this level, it is also important to evaluate its impact at the level of 'activity' (World Health Organization 1999). To measure this, some of the early studies used the Physician's Rating Scale (Koman et al. 1993, 1994; Denislic et al. 1995). Recently, however, the Gross Motor Function Measure (GMFM; Russell et al. 1989) has become more widely used as an outcome measure for children with CP. In three studies this has been used to assess the benefit of BTX-A injections (Flett et al. 1999, Yang et al. 1999, Mall et al. 2000). The Paediatric Evaluation of Disability Inventory (Haley et al. 1992) and the WeeFIM (Msall et al. 1994) could also be used, but these span both 'activity' and 'participation'.

Despite nearly 10 years of use in clinical practice, there is little scientific evidence for an optimum dose of BTX-A in this condition. In previous studies, the doses of Dysport ${ }^{\circledR}$ have varied between 5 units/kg body weight (Cosgrove et al. 1994, Heinen et al. 1997b) and 30 units/kg (Heinen et al. 1997b). 
In 1998 , in a consensus paper, Carr and colleagues (1998) recommended a dose in the range 0.25 to 35 units $/ \mathrm{kg}$, with no more than 200 units per site, and a maximum total dose of 900 to 1000 units per treatment. More recently Bakheit and coworkers (2001) suggested that doses of up to 1000 units/kg do not increase susceptibility to adverse events but were not able to make any definitive conclusions about efficacy. Only one published study (Wissel et al. 1999) has investigated the effects of different doses of BTX-A, but this study was not placebo controlled.

\section{Method}

ETHICAL CONSIDERATIONS

This study was conducted in accordance with the Declaration of Helsinki and its amendments, and in compliance with the guidelines for Good Clinical Practice. It was approved by the National and Local Research Ethics Committee for each of the 12 participating European centres. The study was fully explained to the parent(s) or guardian(s) and all gave written consent before any study-specific assessments were performed. Where possible, the study was also explained to the children themselves.

\section{PARTICIPANTS}

Participants were identified from those attending one of six centres in the UK, one in Ireland, and five in Poland (as identified in the affiliations of the authors). Selection criteria were defined in advance of the start of recruitment. Eligible participants (of either sex) were aged 2 to 9 years, weighed 10 to $25 \mathrm{~kg}$, and were ambulatory (with or without orthoses or walking aids), with a diagnosis of diplegic CP, a dynamic component of more than $1.5 \%$ in at least one leg, and the potential to benefit from administration of BTX-A to the gastrocnemius muscles of both legs. Participants were excluded if they had received treatment with BTX-A within the 9 months before entry, previous phenol treatment for lowerlimb spasticity, or previous surgery on the muscles or ligaments of the lower limb. Those with valgus deformity of the foot or excessive ankle dorsiflexion were also excluded, because the model of gastrocnemius muscle length is not necessarily valid in these participants. Participants having used an investigational drug in the preceding 30 days, with a generalized muscle activity disorder (e.g. myasthenia gravis), or receiving aminoglycoside antibiotics or spectinomycin, were also excluded.

INTERVENTIONS

Participants were randomized to receive either placebo or a total dose of Dysport (Ipsen Ltd, Maidenhead, UK) of 10, 20 or 30 units $/ \mathrm{kg}$. Dysport was supplied in clear vials as a freeze-dried white pellet containing clostridium botulinum type A toxin-haemagglutinin complex. The placebo consisted of the excipient alone. Study medication was supplied to centres in individual patient packs, each containing indistinguishable vials. Each pack contained either one (10 units/kg), two (20 units/kg), three (30 units/kg), or no active vials (placebo group). All four vials were always used, and the contents of each vial were reconstituted with $1.0 \mathrm{ml}$ of sterile saline $(0.9 \% \mathrm{w} / \mathrm{v})$. The vial contents were drawn up into a single syringe, giving a total of $4 \mathrm{ml}$. A fraction of this volume, determined by the weight of the patient (to the nearest kilogram), was taken and made up to the final injec- tion volume of $2 \mathrm{ml}$ with sterile saline $(0.9 \% \mathrm{w} / \mathrm{v})$, so that $0.5 \mathrm{ml}$ could be injected at two sites on the calf of each leg. Patients were treated within 1 hour of reconstitution.

The sites of injection were at the junction of the proximal quarter and the distal three-quarters of the gastrocnemius muscle, determined by palpation of the femoral and calcaneal insertions. The site for injection was confirmed by positioning the limb to produce the maximum stretch in the gastrocnemius, inserting the needle and moving the distal joint through its full range of movement. If positioned correctly, the needle remained at the angle of injection. A sedative (e.g. midazolam) and/or a topical anaesthetic cream. could be used before injection, as required.

Oral antispasticity medication, if it was taken before the start of the study, was continued at the same dose throughout the course of the study. Regular physiotherapy and the use of walking aids and/or orthoses were also permitted, but did not change throughout the study.

OBJECTIVES

The aims of this prospective, multicentre, double-blind, placebo-controlled, dose-ranging study were to assess the efficacy and safety of three different doses of Dysport $(10,20$ and 30 units $/ \mathrm{kg}$ body weight) in the treatment of dynamic equinus spasticity in patients with CP. A full protocol was written before recruitment was started. The primary efficacy measure was identified in this as the change in dynamic component at 4 weeks. Secondary outcome measures were also recorded as described below. The primary safety measure was an assessment of adverse events. The specific hypotheses were that the different treatment groups showed differences from the placebo group. Data were also collected at 8 and 16 weeks to give an indication of the duration of the effect.

OUTCOME MEASURES

Following Eames and colleagues (1999), the change in the dynamic component of gastrocnemius shortening at 4 weeks after injection was taken as the primary outcome measure of efficacy. This was also measured at 8 and 16 weeks to monitor the duration of response. The range of ankle movement on passive examination, assessed at 4,8 , and 16 weeks, and the change in GMFM, assessed at 4 and 16 weeks, were the secondary outcome measures of efficacy. The primary measure of safety was the assessment of spontaneously reported adverse incidents. All baseline measurements were made less than 1 week before administration of the study medication.

Eames and colleagues (1999) measured the dynamic component of gastrocnemius shortening by using 3-D gait analysis. Not all participating centres had access to 3-D gait analysis, so a custom-designed measurement system based on the use of flexible electrogoniometers (Biometrics Ltd, Cwmfelinfach, Gwent, UK) was produced. Standard M-180 units were used to measure knee angle; modified units, with the distal end-block perpendicular to the sensor, were used to measure ankle angle. Before performing any assessment, all equipment was checked and calibrated. Patients were barefoot and dressed in shorts to facilitate the correct positioning of the goniometers. The proximal knee goniometer end-block was oriented along a line from the femoral epicondyle to the centre of the greater trochanter. The distal knee end-block and proximal ankle end-block were both 
placed parallel to a line between the lateral malleolus and the fibula head. The distal ankle end-block was aligned with the plantar surface of the foot with a custom-made alignment plate. The goniometers were connected to a K100 patient unit and, via a cable, to the K100 desktop unit. Output was then fed into a laptop computer. Customized software was written to calculate muscle length as a function of the goniometer measurements, based on the model of Eames et al. (1999), that calculates gastrocnemius length as a function of participant height and sagittal plane knee and ankle angles, measured by 3-D gait analysis.

Assessment of passive muscle length was made with the patient supine and relaxed. With the knee extended, the calf muscle was stretched by dorsiflexing the ankle until a maximum range of movement was obtained. A total of 180 values were recorded over a 30 -second period during which the stretch was maintained. This was repeated twice (three tests in total). Maximum passive muscle length was taken as the 30 th highest value, from a total of 540, recorded from all three tests. This was done to exclude the effects of artefacts in the recorded data.

Data from each leg were collected and analyzed separately. Although the different legs of the same patient are clearly not independent, the direct action to the toxin is (assumed to be) local. The data presented below have been obtained by treating each leg as a separate observation. The results were, however, verified by alternative analyses summarising the measurement across the two legs (e.g. average change from baseline at week 4 across the two legs). Results from these analyses were consistent with the result presented in this paper.

Active muscle length was assessed during a 5-second walk along a $10 \mathrm{~m}$ walkway (300 values recorded). Only the minimum walking aids necessary to ensure reasonable walking ability (e.g. crutches) were permitted. Data from five walking tests were captured. The captured data were filtered with a five-sample moving-average filter and divided into gait cycles. The maximum muscle length recorded during each gait cycle was calculated. Maximum active muscle length was taken as the fourth highest from the individual gait cycle. This removed the effect of occasional abnormal gait cycles showing uncharacteristically long muscle lengths. Data from both legs were captured during all walks, but they were processed separately for each side.

Although the dynamic component of Eames et al. (1999) seems to be the most sensitive measure of the response to injections into the gastrocnemius, the units in which it is measured (difference in muscle length as a percentage of the length in the anatomical position) are difficult to interpret clinically. Clinicians are used to measuring the range of dorsiflexion with the knee extended to assess gastrocnemius length, and the model of Eames et al. (1999) was, therefore, used to calculate the increase in this measurement, which would be equivalent to a given change in the dynamic component. This was carried out for dynamic components in the range 0 to $5 \%$ and for participant height ranging from 500 to $1500 \mathrm{~mm}$.

All electrogoniometer data were checked for consistency before the blinding codes were broken. Data from 5.2\% (52 of 1002) leg assessments were considered unreliable for one or more of the following reasons: missing goniometer measurements, insufficient number of steps recorded, values outside the physiological range, evidence of misplaced goniometers, and electromagnetic interference. After the codes had been broken, the proportion of unreliable data in each group was

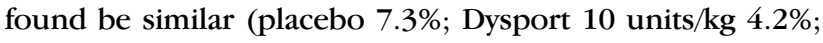
Dysport 20 units/kg 5.4\%; Dysport 30 units/kg 4.1\%).

GMFM was assessed in accordance with the Gross Motor Function Training Manual (Russell 1993). All assessors were fully trained and accredited, and when possible the same assessor performed the assessment at each clinic visit. The total GMFM score was calculated and the scores for dimensions $\mathrm{D}$ (standing) and $\mathrm{E}$ (walk/run/jump) were used to obtain a goal total score.

At each clinic visit the investigator and the parents each made a subjective functional assessment of gait, and rated the patient's response to treatment as 'good' (observable and of functional benefit), 'minimal' (observable but not of functional benefit), 'none' (no observable change) or 'worse' (observable and to the detriment of the participant).

On completion of the study the investigator and the parents made an overall assessment of efficacy by indicating whether they believed that the patient had benefited from treatment or not.

Occurrence of adverse events was monitored at each visit. They were classified as 'severe' (incapacitating and preventing normal everyday activities), 'moderate' (sufficiently discomforting to interfere with normal everyday activities), or 'mild' (easily tolerated by the patient, causing minimal discomfort and not interfering with everyday activities).

SAMPLE SIZE

A power analysis based on the raw data used by Eames et al. (1999) was used to determine sample size. The SD of decrease in dynamic component was $2.1 \%$ of anatomical muscle length. To detect a difference between placebo $(0.5 \%$ decrease assumed) and the highest dose (2.0\% decrease assumed) at $p<0.05$ with $80 \%$ power, 30 patients per group were required. A total sample size of 120 was therefore used. No interim analyses or stopping rules were used.

RANDOMIZATION

The independent contractor (Penn Pharmaceuticals, Tredegar, Gwent, UK) responsible for the preparation of study medication also produced the randomization scheme. A computergenerated randomization scheme produced blocks of four sequential preparation references such that each block allocated each of four participants to the four study groups. Because the preparations were indistinguishable, the randomization scheme was concealed from everyone except the contractor.

Separate subsets of this list were allocated to each centre. After baseline assessments, eligible participants were allocated a number taken either from the beginning of the list (allocated to their centre) or the end, depending on whether the baseline dynamic component was greater than $4 \%$ in one or both legs or not. This scheme thus ensured stratification by centre and baseline component. If all blocks had been used, an equal number of participants in each group would be guaranteed. Slight differences in numbers between groups reflect the partial use of lists from different centres. Generation of the allocation sequence and enrolment of participants were thus completely independent. Assignment of patients to groups was by a fixed protocol entirely dependent on the randomization scheme. 
BLINDING

As outlined above, only the independent contractor was aware of group assignment. Participants, families, clinical staff, and those responsible for assessors were thus all blinded to this. Group assignments were not released until after the final assessment, the completion of the statistical analysis plan, and compilation of all data for that analysis.

STATISTICAL ANALYSES

The primary and secondary outcome variables were subjected to statistical analysis, as were the two measures from which the dynamic component is derived (maximum active and passive gastrocnemius length). The continuous variables (change in dynamic component, maximum active and passive gastrocnemius length, maximum passive dorsiflexion with knee extended or flexed, GMFM overall, and goal score) were analyzed by analysis of covariance. A model consisting of treatment, baseline, centre and baseline dynamic component was fitted to the data, with the baseline dynamic component categorized as either less than $4 \%$ or greater than $4 \%$. The assumptions of normality and homogeneity of variance were assessed by inspection of normal probability plots and residual plots. Standardized residuals versus predicted values and standardized residuals versus covariate plots were also produced to aid the diagnostics. The original statistical analysis plan specified the further use of linear trend analysis within the three dose groups (i.e. excluding placebo). This was to examine doseresponse relationships and was based on the assumption that the response would be an increasing function of dose. The results clearly showed this assumption to be invalid, with the maximum responses occurring in the medium-dose group. Therefore, a quadratic trend analysis was added. This was the only modification to the original analysis plan made after the randomization scheme was revealed.

Ordinal data (parents' and investigators' assessments of functional response and overall efficacy) were analyzed by logistic regression. A similar model of treatment, baseline, and centre was used as for the continuous variables. The $p$ value for the odds ratio of each of the treatment comparisons was taken as an indication of the statistical significance of results.

All hypothesis tests were two-sided and performed using a $5 \%$ level of significance. For each of the analyses performed the data were examined for interactions. The effect of adding treatment by centre and treatment by covariate interactions into the model was assessed. If interactions were found to be statistically significant at the $10 \%$ level $(p<0.10)$, additional

Table I: Demographic data

\begin{tabular}{|c|c|c|c|c|}
\hline & Placebo & $\begin{array}{r}\text { Dysport } \\
10 \text { units } / \mathrm{kg}\end{array}$ & $\begin{array}{r}\text { Dysport } \\
20 \text { units/kg }\end{array}$ & $\begin{array}{r}\text { Dysport } \\
\text { 30units/kg }\end{array}$ \\
\hline$n$ patients & 31 & 36 & 28 & 30 \\
\hline Age, $y^{a}$ & $5.5(2.2)$ & $5.4(2.0)$ & $4.9(1.9)$ & $4.8(2.1)$ \\
\hline Sex, male/female, \% & $55 / 45$ & $64 / 36$ & $46 / 54$ & $47 / 53$ \\
\hline Race, caucasian, \% & 97 & 94 & 100 & 97 \\
\hline Weight, kg ${ }^{\mathrm{a}}$ & $18.7(4.7)$ & $17.7(4.4)$ & $17.3(4.2)$ & $17.3(4.5)$ \\
\hline Height, $\mathrm{m}^{\mathrm{a}}$ & $1.09(0.13)$ & $1.08(0.16)$ & $1.04(0.13)$ & $1.05(4.5)$ \\
\hline
\end{tabular}

${ }^{\mathrm{a} D a t a}$ are presented as mean (SD). covariates were included in the model, to remove the interactions. If the interactions were not statistically significant at this level, they were dropped from the model. The baseline stratified dynamic component was included as a covariate in all models because it was used as a stratification variable in the randomization.

\section{Results}

PARTICIPANTS

A total of 126 participants were recruited to the study across the 12 centres, of whom 124 completed the 16-week assessment. One of these (in the 30 units/kg group) withdrew before treatment and was excluded from the analyses, and another (20 units/kg) was lost to follow-up after the visit in week 8 .

BASELINE DATA

The details of patient demography are presented in Table I. Baseline dynamic component and GMFM data are incorporated in Tables II and III respectively. The treatment groups were well matched with regard to age, sex, race, weight, and height.

\section{ASSESSMENT OF EFFICACY}

\section{Electrogoniometry}

Patients treated with placebo demonstrated only small changes in the dynamic component throughout the 16-week observation period (Table II and Figure 1). However, in the three active treatment groups, reductions in the dynamic component were observed at each time point (Table IV). For each active treatment group the change from baseline at week 4 was statistically significantly different from the placebo group, and a statistically significant quadratic trend analysis suggested that the greatest improvement was in the 20 units/kg group (Table V). The differences between active treatment groups and placebo were greatest at week 4 but were still evident for the 20 units/kg group at week 16 (Table IV).

Table II includes a considerable number of statistical tests and is thus susceptible to identification of false positives. Table $\mathrm{V}$ gives more detailed information on the parameters selected, before the randomization code had been broken, as primary and secondary outcome variables. Variables measured at different assessment times from those of the primary and

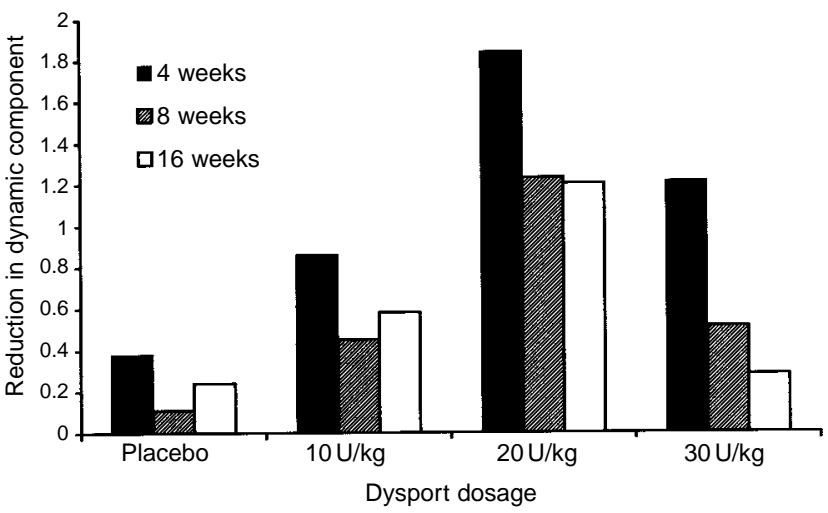

Figure 1:Reduction in dynamic component as measured at 4, 8 , and 16 weeks. All values are expressed as \% of muscle length in anatomical position. Error bars represent standard deviations. 
secondary outcome variables generally show commensurate patterns, giving some confidence that these are genuine positive outcomes.

By definition, changes in dynamic component must be reflected in changes in gastrocnemius muscle length. Maximum passive gastrocnemius length changed little after treatment, and no between-group differences were statistically significant. However, maximum active gastrocnemius length increased in each active treatment group (Table II). The greatest change from baseline was observed at week 4 but was still evident at week 16 . Increases in active gastrocnemius length at week 4 for the 20 and 30 units/kg groups were statistically significantly different from those in the placebo group, but the increase observed in the 10 units $/ \mathrm{kg}$ group failed to reach statistical significance.

Passive ankle dorsiflexion changed little after treatment (Table II) except in the 30 units/kg group, which demonstrated small but statistically significant increases with the knee extended and flexed.

Figure 2 shows the result of the model to propose a more

Table II: Electrogoniometry assessments

\begin{tabular}{|c|c|c|c|c|c|c|c|c|}
\hline & \multicolumn{2}{|r|}{$\begin{array}{c}\text { Placebo } \\
\text { group }\end{array}$} & \multicolumn{2}{|c|}{$\begin{array}{c}\text { Dysport } \\
10 \text { units } / \mathrm{kg}\end{array}$} & \multicolumn{2}{|c|}{$\begin{array}{c}\text { Dysport } \\
20 \text { units } / \mathrm{kg}\end{array}$} & \multicolumn{2}{|c|}{$\begin{array}{c}\text { Dysport } \\
\text { 30 units/kg }\end{array}$} \\
\hline & $n$ & $\operatorname{Mean}(S D)$ & $n$ & $\operatorname{Mean}(S D)$ & $n$ & Mean (SD) & $n$ & $\operatorname{Mean}(S D)$ \\
\hline \multicolumn{9}{|c|}{ Dynamic component, $\%$} \\
\hline Baseline & 56 & $3.4(1.9)$ & 68 & $3.2(1.7)$ & 55 & $3.4(1.7)$ & 56 & $3.3(1.8)$ \\
\hline Week 4 & 54 & $3.3(1.9)$ & 66 & $2.3(1.7)$ & 50 & $1.6(1.4)$ & 58 & $2.0(1.7)$ \\
\hline Week 8 & 57 & $3.5(1.7)$ & 64 & $2.9(1.5)$ & 50 & $2.2(1.2)$ & 59 & $2.7(1.9)$ \\
\hline Week 16 & 57 & $3.2(1.7)$ & 70 & $2.7(1.6)$ & 49 & $2.2(1.4)$ & 57 & $3.0(1.9)$ \\
\hline \multicolumn{9}{|c|}{ Change from baseline } \\
\hline Week 4 & 49 & $-0.38(1.43)$ & 65 & $-0.86(1.14)^{\mathrm{a}}$ & 50 & $-1.84(2.07)^{c}$ & 54 & $-1.21(1.60)^{\mathrm{b}}$ \\
\hline Week 8 & 55 & $-0.11(1.52)$ & 67 & $-0.45(1.36)$ & 55 & $-1.23(1.96)^{\mathrm{c}}$ & 56 & $-0.51(1.19)$ \\
\hline Week 16 & 56 & $-0.24(1.38)$ & 68 & $-0.58(1.38)$ & 55 & $-1.20(1.77)^{c}$ & 56 & $-0.28(1.26)$ \\
\hline \multicolumn{9}{|c|}{ Maximum active gastrocnemius length, \% } \\
\hline Baseline & 56 & $96.8(2.7)$ & 68 & $97.5(2.4)$ & 55 & $97.1(2.3)$ & 58 & $97.1(2.4)$ \\
\hline Week 4 & 54 & $96.8(3.0)$ & 66 & $98.3(2.4)$ & 50 & $99.1(1.7)$ & 58 & $98.2(2.6)$ \\
\hline Week 8 & 57 & $97.0(2.6)$ & 64 & $98.1(2.5)$ & 50 & $98.9(1.8)$ & 59 & $98.0(2.3)$ \\
\hline Week 16 & 57 & $96.8(2.6)$ & 70 & $97.9(2.3)$ & 49 & $98.4(1.8)$ & 57 & $97.3(2.6)$ \\
\hline \multicolumn{9}{|c|}{ Change from baseline } \\
\hline Week 4 & 49 & $0.2(1.7)$ & 65 & $0.7(1.5)$ & 50 & $2.1(2.3)^{\mathrm{c}}$ & 54 & $1.3(1.8)^{b}$ \\
\hline Week 8 & 55 & $0.4(1.9)$ & 67 & $0.8(1.7)$ & 55 & $1.7(2.4)$ & 56 & $0.8(1.6)$ \\
\hline Week 16 & 56 & $0.0(1.9)$ & 68 & $0.5(1.5)$ & 55 & $1.4(2.0)$ & 56 & $0.2(1.8)$ \\
\hline \multicolumn{9}{|c|}{ Maximum passive gastrocnemius length, \% } \\
\hline Baseline & 56 & $100.2(1.9)$ & 68 & 100.7 (1.6) & 55 & $100.5(1.4)$ & 56 & $100.3(2.0)$ \\
\hline Week 4 & 54 & $100.1(2.1)$ & 66 & $100.6(1.8)$ & 50 & $100.7(1.0)$ & 58 & $100.3(1.8)$ \\
\hline Week 8 & 57 & $100.6(2.0)$ & 64 & $101.1(1.9)$ & 50 & $101.1(1.5)$ & 59 & $100.7(2.0)$ \\
\hline Week 16 & 57 & $100.0(1.9)$ & 70 & $100.6(1.7)$ & 49 & $100.5(1.3)$ & 57 & $100.2(1.9)$ \\
\hline \multicolumn{9}{|c|}{ Change from baseline } \\
\hline Week 4 & 49 & $-0.2(1.8)$ & 65 & $-0.2(1.6)$ & 50 & $0.2(1.6)$ & 54 & $0.1(1.6)$ \\
\hline Week 8 & 55 & $0.3(1.89)$ & 67 & $0.4(1.6)$ & 55 & $0.5(1.7)$ & 56 & $0.2(1.6)$ \\
\hline Week 16 & 56 & $-0.2(1.9)$ & 68 & $0.0(1.5)$ & 55 & $0.2(1.6)$ & 56 & $-0.1(1.6)$ \\
\hline \multicolumn{9}{|c|}{ Passive ankle dorsiflexion with knee extended, ${ }^{\circ}$} \\
\hline Baseline & 55 & $8.1(15.0)$ & 66 & $10.1(12.7)$ & 55 & $14.0(17.2)$ & 56 & $9.4(19.4)$ \\
\hline Week 4 & 50 & $8.2(15.6)$ & 62 & $10.2(13.0)$ & 50 & $13.7(15.7)$ & 56 & $10.1(15.9)$ \\
\hline Week 8 & 53 & $7.9(14.6)$ & 60 & $12.0(14.1)$ & 50 & $12.4(15.6)$ & 57 & $10.9(14.4)$ \\
\hline Week 16 & 59 & $4.1(13.6)$ & 69 & $9.7(14.1)$ & 49 & $11.6(12.9)$ & 57 & $9.0(14.7)$ \\
\hline \multicolumn{9}{|c|}{ Change from baseline } \\
\hline Week 4 & 46 & $-0.6(13.5)$ & 61 & $-0.5(10.8)$ & 50 & $-0.6(16.3)$ & 53 & $2.6(14.4)^{\mathrm{a}}$ \\
\hline Week 8 & 52 & $-1.6(12.6)$ & 63 & $-0.1(11.6)$ & 55 & $-2.2(16.7)$ & 55 & $2.7(14.0)$ \\
\hline Week 16 & 55 & $-2.8(14.9)$ & 66 & $-0.9(12.3)$ & 55 & $-2.2(13.2)$ & 56 & $0.9(16.2)$ \\
\hline \multicolumn{9}{|c|}{ Passive ankle dorsiflexion with knee flexed, ${ }^{\circ}$} \\
\hline Baseline & 55 & $21.4(14.3)$ & 66 & $25.3(14.3)$ & 55 & $24.3(17.7)$ & 56 & $21.2(18.2)$ \\
\hline Week 4 & 50 & $22.6(15.4)$ & 62 & $25.9(13.9)$ & 50 & $26.4(17.0)$ & 56 & $23.4(16.7)$ \\
\hline Week 8 & 53 & $24.3(12.6)$ & 60 & $27.0(14.1)$ & 50 & $26.3(17.4)$ & 57 & $24.6(13.9)$ \\
\hline Week 16 & 59 & $16.4(13.3)$ & 70 & 23.7 (12.9) & 49 & $24.3(15.9)$ & 57 & $20.9(15.7)$ \\
\hline \multicolumn{9}{|c|}{ Change from baseline } \\
\hline Week 4 & 46 & $-1.0(13.7)$ & 61 & $0.2(10.8)$ & 50 & $1.0(16.1)$ & 53 & $4.4(11.5)^{\mathrm{a}}$ \\
\hline Week 8 & 52 & $0.1(11.5)$ & 63 & $-0.7(12.0)$ & 55 & $0.6(15.0)$ & 55 & $5.0(11.6)$ \\
\hline Week 16 & 55 & $-4.4(14.4)$ & 66 & $-2.3(11.5)$ & 55 & $-0.1(14.0)$ & 56 & $0.8(13.0)$ \\
\hline
\end{tabular}

${ }^{\mathrm{a}} p<0.05,{ }^{\mathrm{b}} p<0.01,{ }^{\mathrm{c}} p<0.001$. All comparisons are between active treatment group and placebo group. 
clinically meaningful way of describing changes in dynamic component. It can be seen that the equivalent increase in dorsiflexion with the knee extended is very nearly proportional to the increase in dynamic component and, therefore, can be used as an alternative method for presenting results. Each $1 \%$ increase in dynamic component is equivalent to the participant having an extra $10.6^{\circ}$ of dorsiflexion available while walking. For dynamic components of less than $5 \%$ this approximation is accurate to within $1.2^{\circ}$ for participants with heights in the range 500 to $1500 \mathrm{~mm}$.

Gross motor function measurement

Neither the overall nor the goal total GMFM scores showed statistically different changes at either 4 or 16 weeks. Consideration of the mean changes at week 4 (Table III and Fig. 3) suggests a small placebo response. At week 16 the scores for the placebo group had not increased further. However, the scores for the active treatment groups at week 16 had increased further, especially in the higher dose groups.

\section{Subjective assessments of benefit}

The subjective assessments of functional benefit demonstrated substantial agreement between the parents and investigators (Table IV). For all active treatment groups the proportion of patients demonstrating a good response was markedly higher than in the placebo group at all time points. Despite

Table III: Gross motor function measurement

\begin{tabular}{|c|c|c|c|c|c|c|c|c|}
\hline & \multicolumn{2}{|c|}{$\begin{array}{c}\text { Placebo } \\
\text { group }\end{array}$} & \multicolumn{2}{|c|}{$\begin{array}{c}\text { Dysport } \\
10 \text { units } / \mathrm{kg}\end{array}$} & \multicolumn{2}{|c|}{$\begin{array}{c}\text { Dysport } \\
\text { 20 units } / \mathrm{kg}\end{array}$} & \multicolumn{2}{|c|}{$\begin{array}{c}\text { Dysport } \\
\text { 30 units/kg }\end{array}$} \\
\hline & $\bar{n}$ & $\operatorname{Mean}(S D)$ & $\bar{n}$ & $\operatorname{Mean}(S D)$ & $\bar{n}$ & Mean (SD) & $\bar{n}$ & $\operatorname{Mean}(S D)$ \\
\hline \multicolumn{9}{|c|}{ Overall score, $\%$} \\
\hline Baseline & 31 & $70(17)$ & 35 & $73(19)$ & 27 & $71(20)$ & 30 & $69(22)$ \\
\hline Week 4 & 30 & $73(16)$ & 35 & $76(19)$ & 26 & $74(19)$ & 30 & $70(22)$ \\
\hline Week 16 & 31 & $73(17)$ & 35 & $77(18)$ & 26 & $75(18)$ & 30 & $73(21)$ \\
\hline \multicolumn{9}{|c|}{ Change from baseline } \\
\hline Week 4 & 30 & $2.5(4.7)$ & 35 & $2.5(3.1)$ & 26 & $1.4(4.2)$ & 30 & $1.3(9.3)$ \\
\hline Week 16 & 31 & $2.3(10.4)$ & 35 & $3.8(4.2)$ & 26 & $4.4(5.4)$ & 30 & $4.5(5.8)$ \\
\hline \multicolumn{9}{|c|}{ Goal total score, \% } \\
\hline Baseline & 31 & $45(26)$ & 35 & $52(29)$ & 27 & $51(27)$ & 30 & $47(31)$ \\
\hline Week 4 & 30 & $49(27)$ & 35 & $57(29)$ & 26 & $53(27)$ & 30 & $50(31)$ \\
\hline Week 16 & 31 & $49(26)$ & 35 & $58(29)$ & 26 & $55(26)$ & 30 & $53(32)$ \\
\hline \multicolumn{9}{|c|}{ Change from baseline } \\
\hline Week 4 & 30 & $4.1(4.3)$ & 35 & $4.3(4.1)$ & 26 & $2.1(6.7)$ & 30 & $3.3(9.4)$ \\
\hline Week 16 & 31 & $4.1(8.9)$ & 35 & $5.7(6.0)$ & 26 & $5.9(8.1)$ & 30 & $6.3(7.5)$ \\
\hline
\end{tabular}

Scores are presented as a percentage of maximum score possible (100\%).

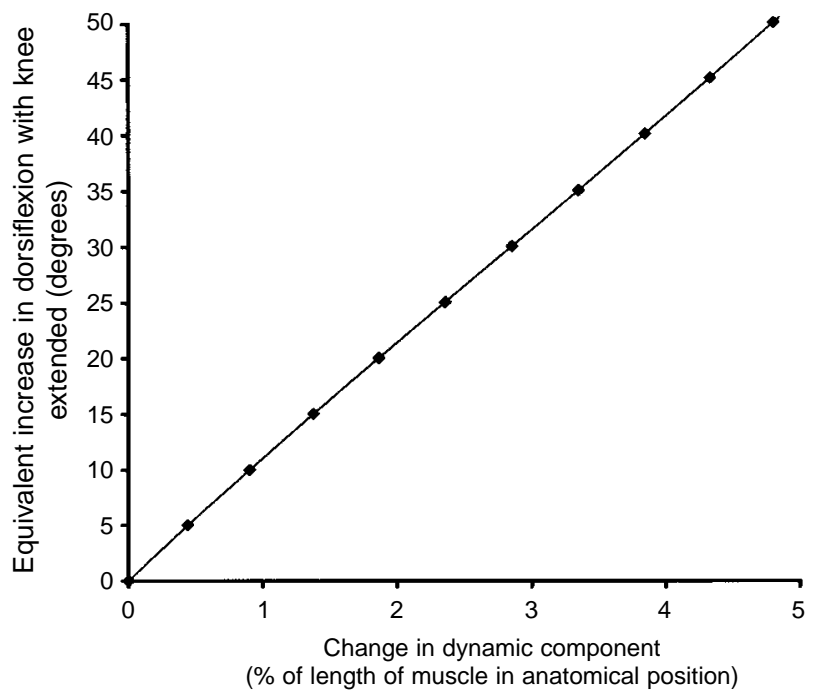

Figure 2: Increase in dorsiflexion with knee extended equivalent to a given change in dynamic component using model of Eames et al. (1999).

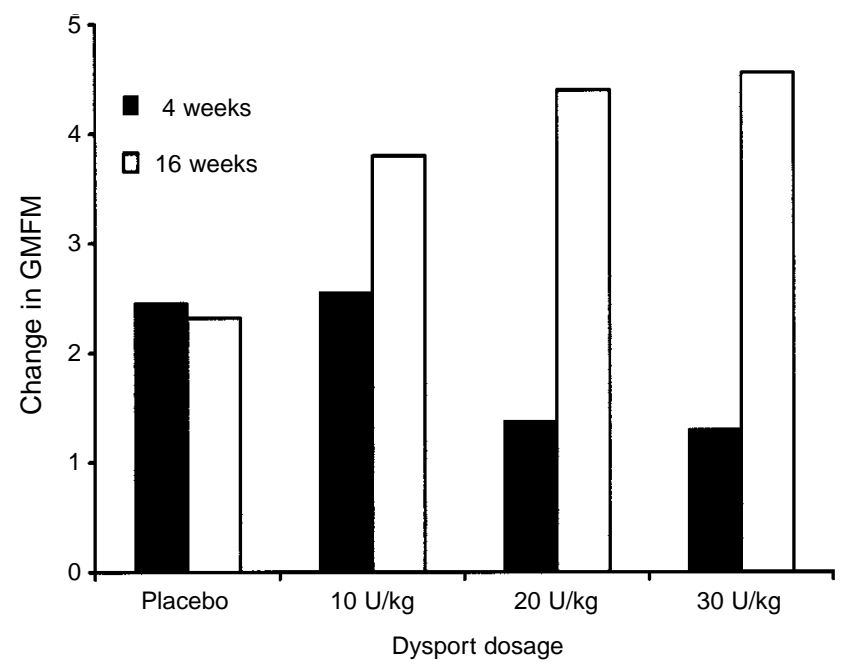

Figure 3: Change from baseline in GMFM overall score at 4 and 16 weeks. All score expressed as \% of total possible score. Error bars represent standard deviations. 
these marked differences, only those for the 30 units $/ \mathrm{kg}$ group at week 4 (parent and investigator) and the 20 units $/ \mathrm{kg}$ group at week 16 (investigator) reached statistical significance (Table V).

The overall assessment of efficacy (Table IV) found that over three-quarters of parents and investigators considered Dysport treatment to be of benefit to the patient, with the parent's assessment of the 30 units/kg group demonstrating statistical significance compared with placebo

ASSESSMENT OF SAFETY

A total of 48 of 94 (51\%) Dysport-treated patients reported 123 adverse events, compared with 10 of 31 (32\%) placebo patients, who reported 20 adverse events. In all treatment groups most adverse events were considered mild (placebo, 12 of 20 [60\%]; Dysport, 85 of 123 [69\%]), and most resolved within 2 weeks of onset (placebo, 14 of 20 [70\%]; Dysport, 89 of 123 [72\%]). No patient withdrew as a result of an

Table IV: Subjective assessments of benefit

\begin{tabular}{|c|c|c|c|c|}
\hline & Placebo & $\begin{array}{r}\text { Dysport } \\
10 \text { units } / \mathrm{kg}\end{array}$ & $\begin{array}{l}\text { Dysport } \\
\text { 20 units } / \mathrm{kg}\end{array}$ & $\begin{array}{r}\text { Dysport } \\
\text { 30 units/kg }\end{array}$ \\
\hline \multicolumn{5}{|c|}{ Parents' assessment of functional response to treatment } \\
\hline Week 4 (total) & 31 & 36 & 27 & 30 \\
\hline Good & 7 & 16 & 12 & $16^{\mathrm{b}}$ \\
\hline Minimal & 14 & 12 & 9 & 11 \\
\hline None & 9 & 8 & 4 & 2 \\
\hline Worse & 1 & 0 & 2 & , \\
\hline Week 8 (total) & 31 & 34 & 28 & 30 \\
\hline Good & 8 & 13 & 12 & 13 \\
\hline Minimal & 13 & 11 & 10 & 14 \\
\hline None & 10 & 10 & 5 & 1 \\
\hline Worse & 0 & 0 & 1 & 2 \\
\hline Week 16 (total) & 31 & 36 & 27 & 30 \\
\hline Good & 6 & 12 & 9 & 8 \\
\hline Minimal & 11 & 15 & 10 & 13 \\
\hline None & 14 & 9 & 7 & 8 \\
\hline Worse & 0 & 0 & 1 & 1 \\
\hline \multicolumn{5}{|c|}{ Investigators' assessment of functional response to treatment } \\
\hline Week 4 (total) & 30 & 36 & 27 & 30 \\
\hline Good & 7 & 16 & 11 & $11^{\mathrm{a}}$ \\
\hline Minimal & 12 & 12 & 9 & 16 \\
\hline None & 11 & 8 & 7 & 2 \\
\hline Worse & 0 & 0 & 0 & 1 \\
\hline Week 8 (total) & 31 & 34 & 28 & 30 \\
\hline Good & 5 & 13 & 10 & 12 \\
\hline Minimal & 16 & 13 & 11 & 13 \\
\hline None & 10 & 8 & 7 & 4 \\
\hline Worse & 0 & 0 & 0 & 1 \\
\hline Week 16 (total) & 31 & 36 & 27 & 30 \\
\hline Good & 6 & 9 & $10 \mathrm{a}$ & 6 \\
\hline Minimal & 11 & 14 & 10 & 15 \\
\hline None & 14 & 13 & 7 & 8 \\
\hline Worse & 0 & 0 & 0 & 1 \\
\hline \multicolumn{5}{|c|}{ Treatment considered to be of benefit at overall assessment of efficacy } \\
\hline Parent & 3118 & $36 \quad 28$ & $27 \quad 21$ & $3025^{\mathrm{a}}$ \\
\hline Investigator & 3120 & 3628 & $27 \quad 22$ & 2924 \\
\hline
\end{tabular}

Results are numbers of participants. ${ }^{\mathrm{a}} p<0.05,{ }^{\mathrm{b}} p<0.01$. adverse event. Table VI presents the overall adverse event profile for the study.

It would be expected, from the known pharmacodynamic properties of Dysport, that most drug-related effects would be evident within 4 weeks of treatment (Scott 1981). Although similar proportions of all reported adverse events occurred during this period for placebo-treated (7 of 20 [35\%]) and Dysport-treated patients ( 44 of 123 [36\%]), the adverse event profile for Dysport-treated patients was notably different from the overall profile, with pain (6\%), falls (5\%), and asthenia (4\%) being the most frequently reported.

Analysis of the adverse events considered to be related to study medication also produced a different profile. No adverse event reported by the placebo group was considered to be related to study medication, whereas 29 of 123 (24\%) adverse events reported by Dysport-treated patients were considered to be related to study medication. The adverse events most frequently considered to be related to study medication were falls $(n=6)$, pain $(n=6)$, and asthenia $(n=4)$.

Table VI also presents the adverse event profiles for each dose group. Similar proportions of patients in the 10 units $/ \mathrm{kg}$ group (21 of 36 patients [58\%]) and the 30 units/kg group (17 of 30 patients [57\%]) reported at least one adverse event, but this proportion was lower in the 20 units/kg group (10 of 28 [36\%]). In terms of the number of adverse events reported by these patients, the 30 units $/ \mathrm{kg}$ group reported the most, with an average of 3.2 events per patient. This was higher than in the two lower-dose groups ( 10 units $/ \mathrm{kg}, 2.2$ events per patient; 20 units $/ \mathrm{kg}, 2.3$ events per patient). There were no statistically significant differences between placebo and any active treatment group for any individual adverse event category.

\section{Discussion}

This double-blind placebo-controlled study has demonstrated a clear improvement in the dynamic component in patients with diplegic CP after treatment with BTX-A, in agreement with the findings of Eames et al. (1999). Because gastrocnemius muscle length is expressed as a percentage of the normal length with the leg in the anatomical position, and the dynamic component is defined as the difference between passive and active muscle lengths, the change in dynamic component is difficult to interpret clinically. However, with the use of the simple model represented by Figure 3 we can equate the $1.8 \%$ change in dynamic component for children receiving Dysport at 20 units $/ \mathrm{kg}$ to an extra $19^{\circ}$ of available dorsiflexion with the knee extended, but it should be noted that this equivalence is a purely theoretical construct representing how much extra dorsiflexion the participant would have if the knee were fully extended during stance: it does not actually require the participant to achieve this. It is also essentially a measure of the change in the length of the muscle while walking and, therefore, does not imply that the extra dorsiflexion should be observed on passive examination. Indeed, the changes observed in the dynamic component were due almost entirely to increases in the length of the gastrocnemius during gait.

One unexpected finding of this study was that the change in dynamic component in the group receiving Dysport at 30 units $/ \mathrm{kg}$ was less than that observed in the 20 units $/ \mathrm{kg}$ group. It is only possible to speculate on the likely reason for this. It might be that the toxin spreads locally. The injection volume was constant for all doses, so it is likely that perfusion was 
similar. It might only be at high doses, however, that the effect on other muscles becomes appreciable. Weakening of the soleus in particular might result in a more crouched gait pattern (this phenomenon is a recognized complication of surgical lengthening of the tendo-Achilles).

If the body weight is to remain in the same position above the base of support, then for every degree of increased dorsiflexion there must be approximately $2^{\circ}$ of increased knee flexion. In this event, because the increase in knee flexion is greater than that in ankle dorsiflexion, the length between gastrocnemius origin and insertion will reduce. Thus, even though the gastrocnemius might be similarly weakened in the 30 and 20 units/kg groups, the recorded active muscle length would be lower in the 30 units/kg group and the reduction in dynamic component would not be as marked. Weakening of any of the extensor muscles might have this effect but the soleus, being so close to the gastrocnemius, is assumed to be the most likely to be affected.

If this analysis is correct, the relaxed gastrocnemius muscle was not being subjected to as great a stretch during walking in the 30 units/kg group. According to the hypothesis of Holly and coworkers (1980) that muscle growth is stimulated by passive stretching, it can be expected that the duration of the effect of the toxin might be reduced if the degree of stretch is reduced. It can indeed be seen (Table II and Fig. 1) that at 16 weeks after treatment with Dysport 20 units $/ \mathrm{kg}$, the mean dynamic component remained at $65 \%$ of that observed at the 4week assessment, whereas the mean value for the $30 \mathrm{units} / \mathrm{kg}$ group had fallen to $23 \%$ of the initial response. Indeed, by 16 weeks the response in the 30 units/kg group was indistinguishable from that in the placebo group.

The raw data on ankle and knee angle were re-analyzed to examine the hypothesis that the 30 units/kg group showed greater knee flexion and dorsiflexion, but the data showed large variability and, although trends were apparent, statistical significance was not achieved. Therefore, the above explanation must remain hypothetical. Despite much consideration of this issue we are unable to suggest any alternative. Whatever

Table V: Differences from placebo group for primary and secondary outcome variables

\begin{tabular}{|c|c|c|c|c|c|c|c|}
\hline & $\begin{array}{r}\text { Time } \\
\text { (weeks) }\end{array}$ & $\begin{array}{r}\text { Units } \\
10 \text { units } / \mathrm{kg}\end{array}$ & $\begin{array}{r}\text { Dysport } \\
20 \text { units } / k g\end{array}$ & $\begin{array}{r}\text { Dysport } \\
30 \text { units } / \mathrm{kg}\end{array}$ & Dysport & Linear trend & Quadratic trend \\
\hline \multicolumn{8}{|l|}{ Primary outcome measure } \\
\hline Dynamic component & 4 & $\%$ anat. length & $\begin{array}{r}-0.6 \\
(-1.2,0.0) \\
p=0.046 f\end{array}$ & $\begin{array}{r}-1.5 \\
(-2.0,-0.8) \\
p<0.001^{f}\end{array}$ & $\begin{array}{r}-1.2 \\
(-1.5,-0.3) \\
p=0.004^{f}\end{array}$ & $\begin{array}{r}n s \\
p=0.303\end{array}$ & $p=0.009$ \\
\hline \multicolumn{8}{|c|}{ Secondary outcome measures } \\
\hline $\begin{array}{l}\text { Max. passive dorsiflexion } \\
\text { (knee extension) }\end{array}$ & 4 & Degrees & $\begin{array}{r}2.8 \\
(-1.5,7.2) \\
p=0.192^{f}\end{array}$ & $\begin{array}{r}4.5 \\
(0.0,9.1) \\
p=0.052^{f}\end{array}$ & $\begin{array}{r}4.6 \\
(-0.1,9.0) \\
p=0.043^{f}\end{array}$ & $\begin{array}{r}n s \\
p=0.416\end{array}$ & $\begin{array}{r}n s \\
p=0.679\end{array}$ \\
\hline $\begin{array}{l}\text { Max. passive dorsiflexion } \\
\text { (knee flexion) }\end{array}$ & 4 & Degrees & $\begin{array}{r}2.3 \\
(-2.8,7.4) \\
p=0.373^{f}\end{array}$ & $\begin{array}{r}2.3 \\
(-3.1,7.6) \\
p=0.404^{f}\end{array}$ & $\begin{array}{r}6.3 \\
(1.0,11.5) \\
p=0.019^{f}\end{array}$ & $\begin{array}{r}n s \\
p=0.112\end{array}$ & $\begin{array}{r}n s \\
p=0.368\end{array}$ \\
\hline GMFM (overall score) & 4 & $\%$ & $\begin{array}{r}0.2 \\
(-2.8,3.2) \\
p=0.877^{f}\end{array}$ & $\begin{array}{r}-1.2 \\
(-4.5,2.0) \\
p=0.448^{f}\end{array}$ & $\begin{array}{c}-1.6 \\
(-4.7,1.6) \\
p=0.326\end{array}$ & N/A & $\mathrm{N} / \mathrm{A}$ \\
\hline GMFM (goal score) & 4 & $\%$ & $\begin{array}{r}0.2 \\
(-3.1,3.5) \\
p=0.900^{f}\end{array}$ & $\begin{array}{r}-1.7 \\
(-5.3,1.8) \\
p=0.335^{f}\end{array}$ & $\begin{array}{r}-1.2 \\
(-5.3,1.8) \\
p=0.472^{f}\end{array}$ & $\mathrm{~N} / \mathrm{A}$ & $\mathrm{N} / \mathrm{A}$ \\
\hline $\begin{array}{l}\text { Subjective functional } \\
\text { assessment (parent) }\end{array}$ & 4 & Odds ratio & $\begin{array}{r}1.9 \\
(0.8,5.1) \\
p=0.160^{t}\end{array}$ & $\begin{array}{r}1.9 \\
(0.7,5.3) \\
p=0.215^{t}\end{array}$ & $\begin{array}{r}4.0 \\
(1.4,11.3) \\
p=0.009^{t}\end{array}$ & $\begin{array}{r}n s \\
p=0.162\end{array}$ & $\begin{array}{r}n s \\
p=0.397\end{array}$ \\
\hline $\begin{array}{l}\text { Subjective functional } \\
\text { assessment (investigator) }\end{array}$ & 4 & Odds ratio & $\begin{array}{r}2.5 \\
(0.92,6.6) \\
p=0.073^{t}\end{array}$ & $\begin{array}{r}2.2 \\
(0.78,6.5) \\
p=0.135^{t}\end{array}$ & $\begin{array}{r}3.3 \\
(1.2,9.4) \\
p=0.026^{t}\end{array}$ & $p=0.571$ & $\begin{array}{r}n s \\
p=0.609\end{array}$ \\
\hline $\begin{array}{l}\text { Overall assessment of } \\
\text { efficacy (parent) }\end{array}$ & 16 & Odds ratio & $\begin{array}{r}0.4 \\
(0.1,1.2) \\
p=0.099^{t}\end{array}$ & $\begin{array}{r}0.4 \\
(0.1,1.6) \\
p=0.194^{t}\end{array}$ & $\begin{array}{r}0.2 \\
(0.1,0.9) \\
p=0.039^{t}\end{array}$ & $\begin{array}{r}n s \\
p=0.527\end{array}$ & $\begin{array}{r}n s \\
p=0.594\end{array}$ \\
\hline $\begin{array}{l}\text { Overall assessment of } \\
\text { efficacy (investigator) }\end{array}$ & 16 & Odds ratio & $\begin{array}{r}0.4 \\
(0.1,1.5) \\
p=0.174^{t}\end{array}$ & $\begin{array}{r}0.3 \\
(0.1,1.2) \\
p=0.093^{t}\end{array}$ & $\begin{array}{r}0.3 \\
(0.1,1.2) \\
p=0.093^{t}\end{array}$ & N/A & N/A \\
\hline
\end{tabular}

${ }^{f} f$-statistic; ${ }^{t} t$-statistic.

Figures shown are a treatment comparison adjusting for effects of baseline, centre, and baseline stratified dynamic component.

Data are presented as mean values, $95 \%$ confidence limits, and $p$ values for statistical significance $(f$-statistic for continuous variables analyzed with analysis of covariance, $t$-statistic for categorical data analyzed on basis of odds ratio).

GMFM, Gross Motor Function Measure; N/A, not analyzed. Linear and quadratic trend analyses were conducted only if at least one treatment group showed a statistically significant treatment effect at $p<0.05$. 
the explanation, it is clear that the magnitude and duration of effects in the 30 units/kg group are lower than those in the 20 units/kg group and that an optimal dose does exist.

At 4 weeks after treatment, overall GMFM scores were similar in each of the treatment groups, and all were slightly higher than baseline (Fig. 3). The score for the placebo group had not increased further by week 16, suggesting that the earlier increase could be due to some learning effect. In contrast, the scores for the active treatment groups continued to increase, with the greatest increases observed in the higherdose groups, suggesting that functional benefit can be maintained at least until week 16 . It is possible that the initial gastrocnemius muscle weakening has an adverse impact on motor function. However, although this direct effect of the toxin on the muscle occurs over a number of days, it would be expected that it would take considerably longer for children to learn how to build on these changes to improve gross motor function. Thus it is probable that the changes observed at 16 weeks after treatment result from a reduced weakening of the muscle in combination with newly learnt changes in motor function on the part of the patients themselves.

However, caution should be used when drawing conclusions from the GMFM data because no between-group differences reached statistical significance, possibly owing to low patient numbers. It is also possible that the GMFM is not sensitive enough to detect the functional improvements that were subjectively reported in this study. The GMFM is designed to assess whether patients can perform various functions but does not assess how well each function is per- formed. It is, therefore, unable to detect improvements in the quality of function.

A notable aspect of the subjective assessments of efficacy is the sizeable proportion of patients in the placebo group who were considered to have demonstrated a good response to treatment. Although such subjective assessments have a place in clinical research, this study indicates the potential for misinterpretation and demonstrates the importance of incorporating an appropriate control group. Despite checks to try and ensure independence of assessors' and parents' opinions, it is almost certain that there is some influence of one on the other and the importance of differences or similarities in these data should not be over interpreted.

This study has also demonstrated that the doses of Dysport used in this study were safe in the population of patients studied. The few reports of possible toxin-related adverse events such as calf pain and increased frequency of falls (due to leg muscle weakness) were mild and transient, and could probably be minimized in clinical practice by appropriate dose titration.

In conclusion, this study has demonstrated that Dysport (10 to 30 units $/ \mathrm{kg}$ ) is safe and effective in the treatment of paediatric dynamic equinus spasticity associated with $\mathrm{CP}$. From the evidence presented, it is reasonable to conclude that a dose of 20 units $/ \mathrm{kg}$ would be an optimal starting dose. The effects had started wearing off by 16 weeks but were still clearly present.

Accepted for publication 31st May 2002.

Table VI: Adverse event incidence

\begin{tabular}{|c|c|c|c|c|c|}
\hline & Placebo & $\begin{array}{r}\text { All Dysport } \\
\text { groups }\end{array}$ & $\begin{array}{r}\text { Dysport } \\
10 \text { units } / \mathrm{kg}\end{array}$ & $\begin{array}{r}\text { Dysport } \\
20 \text { units/kg }\end{array}$ & $\begin{array}{r}\text { Dysport } \\
\text { 30 units } / \mathrm{kg}\end{array}$ \\
\hline Patients & 31 & 94 & 36 & 28 & 30 \\
\hline Patients with adverse events & 10 & 48 & 21 & 10 & 17 \\
\hline Pharyngitis & 1 & 9 & 5 & 1 & 3 \\
\hline Fever & 3 & 8 & 5 & 2 & 1 \\
\hline Pain & 2 & 8 & 4 & 0 & 4 \\
\hline Falls & 0 & 7 & 1 & 3 & 3 \\
\hline URTI & 0 & 6 & 2 & 2 & 2 \\
\hline Infection & 1 & 6 & 2 & 2 & 2 \\
\hline Bronchitis & 0 & 5 & 3 & 1 & 1 \\
\hline Viral infection & 0 & 5 & 4 & 0 & 1 \\
\hline Asthenia & 0 & 4 & 0 & 2 & 2 \\
\hline Asthma & 0 & 4 & 1 & 1 & 2 \\
\hline Cough increased & 4 & 4 & 4 & 0 & 0 \\
\hline Convulsion & 2 & 4 & 2 & 0 & 2 \\
\hline Vomiting & 0 & 4 & 2 & 2 & 0 \\
\hline Cold & 1 & 3 & 1 & 2 & 1 \\
\hline Diarrhoea & 0 & 3 & 2 & 1 & 0 \\
\hline Gastroenteritis & 0 & 2 & 0 & 0 & 2 \\
\hline Somnolence & 0 & 2 & 0 & 0 & 2 \\
\hline Adverse events & 20 & 123 & 46 & 23 & 54 \\
\hline Adverse events per patient & 2.0 & 2.6 & 2.2 & 2.3 & 3.2 \\
\hline
\end{tabular}

Adverse event incidence is presented as number of patients reporting each adverse event. Adverse events are categorized by COSTART (US Food and Drug Administration, Center for Drug Evaluation and Research 1995) preferred term and only those reported by at least two patients in any treatment group are presented. URTI, upper respiratory tract infection. 


\section{Acknowledgements}

We thank the following personnel at each investigative site who made a significant contribution to the success of this study: $\mathrm{J}$ Taczala (Lublin, Poland); J Slawek (Gdañsk, Poland); A Oskedra (Warsaw, Poland); T Krzeczyńska-Zardecka, Z Kalinowski (Zagórze, Poland); K Herring, L Katchburian (Great Ormond Street Hospital, London, UK); S Gibb, J Linskell (Dundee, UK); E Will (Guys Hospital, London, UK); A Kennedy (Dublin, Eire); N Thompson, M Harrington (Oxford, UK); I Indisow, K Kolodziejczyk-Klimek, D Sokolowska, M Tosik (Lódź, Poland); F Eckford, V Young, E Hazelwood (Edinburgh, UK); and K McCarthy (Belfast, UK). This study was sponsored by Ipsen Limited, 1 Bath Road, Maidenhead, Berkshire, UK.

\section{References}

Bakheit AMO, Severa A, Cosgrove A, Morton R, Roussounis SH, Doderlein L, Lin J-P. (2001) Safety profile and efficacy of botulinum toxin A (Dysport) in children with muscle spasticity. Developmental Medicine \& Child Neurology 43: 234-8.

Boyd RN, Pliatsois V, Starr R, Wolfe R, Graham HK. (2000) Biomechanical transformation of the gastroc-soleus muscle with botulinum toxin A in children with cerebral palsy. Developmental Medicine \& Child Neurology 42: 32-41.

Calderon-Gonzalez R, Calderon-Sepulveda R, Rincon-Reyes M, Garcia-Ramirez J, Mino-Arango E. (1994) Botulinum toxin A in management of cerebral palsy. Pediatric Neurology 10: 284-8.

Carr LJ, Cosgrove AP, Gringas P, Neville BGR. (1998) Position paper on the use of botulinum toxin in cerebral palsy. UK Botulinum Toxin and Cerebral Palsy Working Party. Archives of Diseases in Childhood 79: 271-3.

Chutorian A, Root L, Botox Study Group. (1995) A multicentre, randomised, double-blind, placebo controlled trial of botulinum toxin type-A (BTA) in the treatment of lower limb spasticity in paediatric cerebral palsy. Movement Disorders 10:364.

Corry I, Cosgrove A, Duffy C, McNeill S, Taylor T, Graham H. (1998) Botulinum toxin A compared with stretching casts in the treatment of spastic equinus: a randomised, prospective trial. Journal of Pediatric Oncology 18: 304-11.

Corry IS, Cosgrove AP, Duffy CM, Taylor TC, Graham HK. (1999) Botulinum toxin A in hamstring spasticity. Gait and Posture 10: $206-10$

Corry IS, Cosgrove AP, Walsh EG, McClean D, Graham HK. (1997) Botulinum toxin A in the hemiplegic upper limb: a double blind trial. Developmental Medicine \& Child Neurology 39: 185-93.

Cosgrove AP, Corry IS, Graham HK. (1994) Botulinum toxin in the management of the lower limb in cerebral palsy. Developmental Medicine \& Child Neurology 35: 379-85.

Denislic M, Meh D. (1995) Botulinum toxin in the treatment of cerebral palsy. Neuropediatrics 26: 249-52.

Eames NW, Baker R, Hill N, Graham K, Taylor T, Cosgrove A. (1999) The effect of botulinum toxin A on gastrocnemius length: magnitude and duration of response. Developmental Medicine $\&$ Child Neurology 41: 226-32.

Flett PJ, Stern LM, Waddy H, Connell TM, Seeger JD, Gibson SK. (1999) Botulinum toxin A versus fixed cast stretching for dynamic calf tightness in cerebral palsy.Journal of Paediatric Child Health 35: 71-7.

Friedman A, Diamond M, Johnston MV, Daffner C. (2000) Effects of botulinum toxin A on upper limb spasticity in children with cerebral palsy. AmericanJournal of Physical Medicine and Rebabilitation "9: 53-9.

Haley SM, Coster WJ, Ludlow LH. (1992) Development and validation of the Pediatric Evaluation of Disability Inventory (PEDI) Archives of Physical Medicine and Rehabilitation '73: 987-8.

Heinen F, Mall V, Wissel J, Bernius P, Stücker R, Linder M, Philipsen A, Korinthenberg R. (1997a) Neue Möglichenkeiten in der Bahandlung spastischer Bewegensstörungen. Monatsschrift Kinderbeilkunde 145: 1088-92.

Heinen F, Wissel J, Philipsen A, Mall V, Leititis JU, Schenkel A, Stucker R, Korinthenberg R. (1997b) Interventional neuropediatrics: treatment of dystonic and spastic muscular hyperactivity with botulinum toxin A. Neuropediatrics 28: 307-13
Hesse S, Luecke D, Malezie M, Bertelt C, Friedrech H, Gregoric M, Mauritz K-H. (1994) Botulinum toxin treatment for lower limb extensor spasticity in chronic hemiparetic patients. Journal of Neurology, Neurosurgery \& Psychiatry 5\%: 1324-.

Holly RG, Barnett JG, Ashmore CR, Taylor RG, Mole PA. (1980) Stretch-induced growth in chicken wing muscles: a new model of stretch hypertrophy. American Journal of Physiology 238: $\mathrm{C} 62-71$

Koman LA, Mooney JF, Smith B, Goodman A, Mulvaney T. (1993) Management of spasticity in cerebral palsy with botulinum toxin A: preliminary investigation.Journal of Pediatric Orthopaedics 13: 489-95.

Koman LA, Mooney JF III, Smith BP, Goodman A, Mulvaney T. (1994) Management of spasticity in cerebral palsy with botulinum-A toxin: report of a preliminary, randomized, double-blind trial. Journal of Pediatric Orthopaedics 14: 299-303.

Koman LA, Mooney JF III, Smith BP, Walker F, Leon JM. (2000) Botulinum toxin type A neuromuscular blockade in the treatment of lower extremity spasticity in cerebral palsy: a randomized, double-blind, placebo-controlled trial. Botox Study Group.Journal of Pediatric Orthopaedics 20: 108-15.

Mall V, Heinen F, Kirschner J, Linder M, Stein S, Michaelis U, Bernius P, Lane M, Korinthenberg R. (2000) Evaluation of botulinum toxin A therapy in children with adductor spasm by gross motor function measure. Journal of Child Neurology 15: $214-7$.

Mousny M, Allington N. (1999) Utilisation de la toxine botulique dans les déformations dynamiques spastiques en équin chez les enfants porteurs d'une infirmité motrice cérébrale. Revue de Chirurgie Orthopédique et Réparatrice de l'Appareil Moteur 85: 156-63.

Msall ME, DiGaudio K, Duffy LC, LaForest S, Braun S, Granger CV. (1994) WeeFIM. Normative sample of an instrument for tracking functional independence in children. Clinical Pediatrics (Philadelphia) 33: 431-8.

Russell DJ, Rosenbaum PL, Cadman DT, Gowland C, Hardy S, Jarvis S. (1989) The gross motor function measure: a means to evaluate the effects of physical therapy. Developmental Medicine $\&$ Child Neurology 31: 341-52.

Russell D, Rosenbaum P, Gowland G, Hardy S, Lane M, Plews N, McGavin H, Cadman D, Jarvis S. (1993) Gross Motor Function Measure Manual. 2nd edn. Hamilton, Canada: McMaster University.

Sanchez-Carpintero R, Narbona J. (1997) Botulinum toxin in spastic infantile cerebral palsy: results in 27 cases during one year. Revue Neurologique 25: 531-5.

Scott AB. (1981) Botulinum toxin injection of eye muscles in correct strabismus. Transactions of the American Ophthalmic Society \%9: 734-770.

Sutherland DH, Kaufman KR, Wyatt MP, Chambers HG, Mubarak SJ. (1999) Double-blind study of botulinum A toxin injections into the gastrocnemius muscle in patients with cerebral palsy. Gait $E$ Posture 10: 1-9.

US Food and Drug Administration, Center for Drug Evaluation and Research (1995) Coding Symbols for Thesaurus of Adverse Reaction Terms. 5th edn. Rockville, MD: US Food and Drug Administration, Center for Drug Evaluation and Research.

Wissel J, Heinen F, Schenkel A, Doll B, Ebersbach G, Muller J, Poewe W. (1999) Botulinum toxin A in the management of spastic gait disorders in children and young adults with cerebral palsy: a randomized, double-blind study of 'high-dose' versus 'low-dose' treatment. Neuropediatrics 30: 120-4.

World Health Organization. (1999) International Classification of Impairment, Disability and Handicap (ICIDH-2) - Draft. Geneva: World Health Organization.

Yang TF, Chan RC, Chuang TY, Liu TJ, Chiu JW. (1999) Treatment of cerebral palsy with botulinum toxin: evaluation with gross motor function measure. Journal of the Formosan Medical Association 98: 832-6. 